\title{
Open-heart techniques and mitral valve plasty for mitral regurgitation in toy- and small-breed dogs: A review
}

\author{
Isamu Kanemoto ${ }^{1,2^{*}}$, Kippei Mihara ${ }^{1,3}$ and Keiichi Sato ${ }^{1,4}$ \\ ${ }^{1}$ Cardiac Surgery Team, Chayagasaka Animal Hospital, Nagoya, Japan \\ ${ }^{2}$ School of Medicine, Institute for Laboratory Animal Research, Nagoya University, Nagoya, Japan \\ ${ }^{3}$ Joint Graduate School of Veterinary Medicine, Kagoshima University, Kagoshima, Japan \\ ${ }^{4}$ School of Medicine, Nagoya University, Nagoya, Japan
}

\begin{abstract}
In human medicine, in the past, open-heart techniques for low-bodyweight children and newborn babies with congenital heart disease were more difficult than high-bodyweight adults. In toy- and small-breed dogs with mitral regurgitation (MR), an acquired heart disease, these techniques are more difficult to perform than for congenital heart diseases in young medium-sized or large dogs because of old age and low body weight. Therefore, improved openheart techniques and mitral valve surgery for severe MR in older toy- and small-breed dogs are essential. Through our surface-cooling hypothermia (sHT) studies, we designed a new, improved open-heart method, namely, "the lowflow cardiopulmonary bypass (CPB) combined with deep sHT in toy- and small-breed dogs (Japan method)"; sHT was later replaced by blood-cooling hypothermia (bHT). At the same time, we devised a new, improved mitral valve plasty (MVP) applicable to severe MR, instead of mitral valve replacement, in toy- and small-breed dogs. This MVP technique was combined with artificial chordal reconstruction, semi-circular suture annuloplasty (AP), and direct scallop-suture valvuloplasty. These MVP techniques are simple, durable, and lead to good long-term quality of life in toy- and small-breed dogs. This review highlights the benefits of our improved CPB and MVP techniques (Japan method) for severe MR in toy-and small-breed dogs, which have led to a high success rate for MVP in severe clinical MR cases in Japan. It may further contribute to the development of more robust techniques for MR in toy- and smallbreed dogs. This also represents the first comprehensive review of the history of open-heart surgery, CPB techniques, and MVP methods for MR in toy- and small-breed dogs.

Keywords: Direct scallop-suture valvuloplasty, Mitral regurgitation, Mitral valve plasty, Open-heart techniques, Toy and small dogs.
\end{abstract}

\section{Introduction}

Mitral regurgitation (MR), an acquired heart disease, has a high incidence and is responsible for threefourth of congestive heart failure cases among dogs. Moreover, it occurs more frequently in older toy- and small-breed dogs (Kittleson and Kiene, 1998). Although MR is usually managed by medical treatment during the moderate to the severe stage (American College of Veterinary Internal Medicine (ACVIM) stage B2-C), it progresses gradually with the lapse of time (Atkins $e t$ al., 2009). If it progresses to the final stage (ACVIM stage $\mathrm{C}-\mathrm{D}$ ) and pulmonary edema cannot be controlled by medical treatment, surgical treatment of MR has been recommended as the final procedure in humans (Kouchoukos et al., 2013d).

At present, some textbooks on open-heart surgery techniques recommend using $\mathrm{CPB}$ in veterinary medicine (Holmberg, 1933; Orton, 2003). These techniques are similar CPB techniques for humans and are applied to treat many congenital heart diseases in medium-sized or large dogs (Klement et al., 1987a, 1987b; Komtebedde et al., 1993; Orton et al., 2005).
Worldwide, early open-heart surgery using CPB has been mostly performed based on collaborative research of veterinary and medical doctors in the universities or research institutes. Therefore, there are few reports on CPB techniques in small dogs, although MR is frequently observed in toy- and small-breed dogs.

Before 2010, there was only one report (Lew et al., 1997) dealing with experimental open-heart techniques using low-flow hypothermic CPB in small dogs, except for our clinical report on CPB study (Kanemoto et al., 2010) in toy- and small-breed dogs. In 1976, there was only one case report of successful mitral valve replacement (MVR) using CPB for MR in a largebreed dog (Eyster et al., 1976). In small dogs, surgical treatment of MR was considered impossible until 1990, when we successfully repaired moderate MR with mitral valve plasty (MVP) using deep sHT in a smallbreed dog (Kanemoto et al., 1990). However, it was difficult to repair severe MR with only sHT because it required a long aortic cross-clamp (ACC) time of more than 1 hour. In 1996, a veterinary team with a pediatric cardiologist conducted a successful MVP in a 
small-breed dog using the human MVP technique and child CPB circuit (Boggs et al., 1996); however, they did not continue using this technique. Thereafter, there has been no report of MVP in a small-breed dog until ours on a new improved open-heart surgery method combined with sHT and CPB (Kanemoto et al., 2001, 2004, 2009, 2010). Safety of open-heart techniques permitting a long ACC time and adopting the MVP method instead of MVR has not yet been confirmed in toy- and small-breed dogs with severe MR.

Over the years, we have studied and improved on these techniques, which are adoptable for severe MR in toyand small-breed dogs, with only veterinary doctors in our hospital. In this paper, we review our new, improved open-heart techniques and MVP methods in toy- and small-breed dogs in relation to human methods. All the experimental studies, stated in this review, were performed in accordance with appropriate ethical considerations.

Open-heart techniques for MR in toy- and smallbreed dogs

Literature review of open-heart surgery in humans and dogs

There are only a few reviews about open-heart surgery in dogs (Kanemoto, 2005; Pelosi et al., 2013). Therefore, herein, we describe our experience regarding open-heart surgery in toy- and small-breed dogs, in comparison to that in humans (Kouchoukos et al., 2013a).

In the history of open-heart surgery, sHT was developed as the first technique (Bigelow et al., 1950a, 1950b). The cross circulation bypass method (Cohen and Lillehei, 1954; Lillehei et al., 1955) performed in a child and an adult was developed as the second technique, although it was later discontinued due to lack of safety. Ultimately, the CPB method (Gibbon, $1937,1954)$ was developed as the third technique. However, there were several problems since the initial CPB machine (especially artificial lung) was very large, and only large animals (big dogs and sheep) were used in experimental CPB studies for humans to improve the function of the $\mathrm{CPB}$ machine. Therefore, clinical open-heart surgery using CPB was started for high-bodyweight young children or adults and large dogs (Eyster et al., 1976), and was delayed in lowbodyweight children and small-size dogs.

Our study of open-heart surgery in a small dog was started with sHT using ether anesthesia (Kanemoto et al., 1985, 1987), followed by a transient early CPB method combined with sHT during cooling and blood warming using a heart-exchanger during rewarming in small dogs (Kanamoto et al., 2003). Since then, it has been performed with blood cooling and rewarming using a heart-exchanger. Therefore, our open-heart studies are described in order below, along with these trends.

Surface-cooling deep hypothermia (HT)

Bigelow et al. (1950b) developed sHT in experimental dogs, which proved the possibility of recovery after circulatory arrest (CA) time of 15 minutes at a rectal temperature (RT) of $20^{\circ} \mathrm{C}$ and that it might be useful in cardiac surgery. In addition, they reported that oxygen consumption dropped from $100 \%$ at $37^{\circ} \mathrm{C}$ to about $20 \%$ at $20^{\circ} \mathrm{C}$ using sHT (Bigelow et al., 1950a). Lewis and Taufic (1953) reported a successful repair of an atrial septal defect in a 5-year-old girl weighing $13.4 \mathrm{~kg}$ with a CA time of 5.5 minutes using this moderate sHT (RT: $26^{\circ} \mathrm{C}$ ); this was the first successful open-heart surgery in the world. However, the CA time was very short (approximately 10 minutes) in the early sHT method because there was no cardioplegia.

In 1956, however, Watanabe et al. (1956) developed a new sHT method using ether anesthesia and acquired a long CA time over 60 minutes in experimental dogs, using the Japan method (Spohn et al., 1959). In veterinary medicine, there are some reports of open-heart surgery using sHT in dogs (Breznock et al., 1971; Weirich et al., 1973).

Up to this era, CA time using sHT was very short because only simple ACC was used. Since this era, however, crystalloid cardioplegia using a high dose of potassium was gradually used in sHT and CPB. In 1980, we started the study of sHT using ether anesthesia and cardioplegia (Young solution; Brown et al., 1956), because it seemed that small dogs are appropriate for easy surface cooling and rewarming, although large dogs are suitable for CPB because of easy blood cooling and warming using heat exchangers. The advantages and disadvantages of both methods are in contrast to each other.

We succeeded in experimental studies on sHT using ether anesthesia and cardioplegia (Young solution + oxygenated Glucose-Insulin-Kalium (GIK) solution; Lolley et al., 1974) with a CA time of 60 minutes at an esophageal temperature (ET) of $20^{\circ} \mathrm{C}$ (Kanemoto et al., $1985,1987,2003)$. We also succeeded in experimental auto-heart transplantation in a puppy during 76 minutes of CA time at an ET of $19^{\circ} \mathrm{C}$ using this sHT method (Kanemoto et al., 1989).

In 1990, we applied this sHT method to a clinically moderate MR case in a 7-year-old small-breed (Maltese) dog weighing $3.8 \mathrm{~kg}$ and succeeded in performing MVP during 40 minutes of CA time at an ET of $21.5^{\circ} \mathrm{C}$; this was the first successful MVP case in veterinary medicine (Kanemoto et al., 1990).

\section{CPB with HT in children}

In 1961, the "Drew method" combined with profound bHT using a heat-exchanger and $\mathrm{CPB}$ using a biventricular bypass was developed as an open-heart method for children, and this method became popular in Europe (Drew, 1961). In 1963, the "Tohoku University method" (Horiuchi, 1963) combined with sHT and Young solution, and hot oxygenated blood coronary perfusion at early rewarming was developed in baby, and this method became popular in Seattle, USA (Dillard et al., 1967; Mohri et al., 1969). In 1967, the "Kyoto University method" (Hikasa et al., 1967, 1968) combined with sHT and Young solution, transferred to $\mathrm{CPB}$ just before $\mathrm{ACC}$, and controlled blood rewarming using a heat-exchanger was developed in children, and 
this method became popular in New Zealand (BarrattBoyes et al., 1971), and then later worldwide. In 2000, we started the study of CPB combined with sHT and cardioplegia (St Thomas II solution), and blood rewarming using a heat-exchanger, and demonstrated excellent results in low-bodyweight small-breed dogs (Kanemoto et al., 2001, 2004, 2009, 2010).

Our CPB techniques with HT in toy-and small-breed dogs

There were some problems with adopting the same CPB technique, similar to that of humans (Davis et al., 2008), in small dogs because of the small body size and operative field, and the small heart size similar to the neonatal infant.

The first problem was related to thoracotomy. Median sternotomy is usually used for flat chests in humans. However, we selected intercostal thoracotomy for V-shaped or barrel-shaped chests in dogs because both atria were located dorsal to the heart, and the open-heart method usually approached the atriotomy. In addition, it seemed that intercostal thoracotomy was not more invasive than median sternotomy.

The second problem was related to access vessels of drain and sending tubes for CPB. These tubes are usually applied to large central vessels [two venae cavae and the aorta (AO)] for median sternotomy in humans (Khonsari and Sintek, 2003). However, the access vessels for $\mathrm{CPB}$ were changed to the peripheral blood vessels, jugular vein, and carotid artery for left or right intercostal thoracotomy because of the small operative field. We also thought these vessels for CPB access are larger than the femoral vein and artery and more nearer to the heart. Moreover, we selected "the low-flow CPB combined with deep HT" method because high-flow CPB using peripheral vessels was difficult.

The third problem was excessive hemodilution due to the relatively large circuit packing volume against small body size. First, we used a minimal small volume circuit and added donor blood. Additionally, the cardioplegic solution volume was decreased to half of the usual volume $(20 \mathrm{ml} / \mathrm{kg})$ to avoid more hemodilution, although we used the lowest deep HT (ET $20^{\circ} \mathrm{C}$ ) for cardioplegia. Thereafter, we used a hemoconcentrator to prevent excess hemodilution due to additional cardioplegic solution (Taguchi et al., 2014; Mihara et al., 2017; Yokoyama et al., 2017).

The fourth problem was the cooling methods, either sHT or bHT. Through our sHT studies, we selected sHT during cooling and blood warming during rewarming using the $\mathrm{CPB}$ heat-exchanger as the slow cooling using sHT and fast rewarming using the heat-exchanger may result in stable hemodynamics and have little adverse effects of quick bHT in toy-and small-breed dogs. Moreover, it seemed to shorten the pump time.

By resolving these problems, in 2010, we reported our new improved method, "The low-flow CPB combined with deep sHT in toy- and small-breed dogs (Japan method)" (Kanemoto et al., 2010). In 1997, Lew et al. (1997) reported the same method (low-flow CPB using deep HT) in small dogs. However, their methods differed widely from our methods as described below: (1) experimental normal small dog weighing 7.7-9.2 $\mathrm{kg}$ versus a toy- and small-breed dog, with clinically severe MR, weighing 2.0-5.3 kg, (2) profound bHT (nasopharyngeal temperature $15^{\circ} \mathrm{C}-18^{\circ} \mathrm{C}$ ) versus deep sHT (ET $\left.19.8^{\circ} \mathrm{C}-23.8^{\circ} \mathrm{C}\right)$, (3) low perfusion flow $(20 \mathrm{ml} /$ $\mathrm{kg} /$ minutes) versus mean lowest pump flow (PF) (29.2 $\mathrm{ml} / \mathrm{kg} /$ minutes), (4) median sternotomy versus intercostal thoracotomy, and (5) drain tube from the big right atrium (RA) versus the small jugular vein. Further, they stated that the technique was more difficult in small-bodyweight dogs than in large-bodyweight dogs. However, we had a high operative success rate in many clinically severe MR cases using these CPB techniques, compared to only sHT, in toy- and small-breed dogs weighing less than $5 \mathrm{~kg}$ (Kanemoto et al., 2001, 2004, 2009, 2010).

Actual stream of initial CPB method using sHT and blood rewarming for MVP in small dogs

Under anesthesia for sHT + CPB (Table 1), heavy premedication was used to prevent shivering by blocking the autonomic nerve during deep sHT. Dogs were administered hydroxyzine hydrochloride $[1 \mathrm{mg} /$ $\mathrm{kg}$ intramuscularly (IM)], acepromazine maleate $(0.05 \mathrm{mg} / \mathrm{kg} \mathrm{IM})$, and atropine sulfate $(0.025 \mathrm{mg} / \mathrm{kg}$ IM) twice at 1 hour and at 30 minutes, followed only acepromazine maleate $0.05 \mathrm{mg} / \mathrm{kg} \mathrm{IM}$ at 15 minutes before inducing anesthesia with thiamylal sodium [12.5 $\mathrm{mg} / \mathrm{kg}$ intravenously (IV)]. After intubation, anesthesia was maintained with $2 \%-2.5 \%$ isoflurane in oxygen. Isoflurane concentration was gradually reduced from $2 \%$ at cooling to $1.5 \%$ at an ET of $30^{\circ} \mathrm{C}, 1 \%$ at an ET of $25^{\circ} \mathrm{C}$, and $0 \%$ during ACC. Isoflurane concentration was maintained at $1 \%$ from aortic declamping to the end of surgery. Pancuronium bromide $(0.04 \mathrm{mg} / \mathrm{kg}$ IV) was administered at the beginning of cooling, and intermittent positive pressure ventilation (tidal volume $=15 \mathrm{ml} / \mathrm{kg}$, ventilation frequency $=20 /$ minutes) using a volume-type ventilator was initiated. During cooling, dexamethasone $(4 \mathrm{mg} / \mathrm{kg}$ IV) was administered with low-molecular-weight dextran $(5 \mathrm{ml} / \mathrm{kg}$ at 10 $\mathrm{ml} / \mathrm{kg} /$ hours $)$. Cefazolin (20 $\mathrm{mg} / \mathrm{kg})$ was injected subcutaneously before and after the surgery.

During MVP, the patient dog was positioned in the right recumbent position. A small drain tube ( $8-10 \mathrm{Fr}$.) up to the maximal big size was inserted from the left jugular vein (LJV) into the RA, and a small sending tube (6-8 Fr.) up to the maximal big size was inserted into the left carotid artery (LCA) directed to the heart. Then, the two tubes were connected to the CPB circuit and stand by (Fig. 1). Next, the dog was covered with a vinyl sheet and dipped into ice water. After the ET reached $23^{\circ} \mathrm{C}$, the dog was taken out from the ice bath and ready for sterilization. Left fifth intercostal thoracotomy was performed. The pericardium was cut horizontally along the left vagal nerve and was made into a hammock to sling the heart. A root cannula for 
Table 1. Anesthetic drugs and cardioplegia in each open-heart technique.

\begin{tabular}{|c|c|c|}
\hline & sTH $^{\mathrm{a}}$ & $\mathbf{T H}+\mathbf{C P B}^{\mathrm{b}}$ \\
\hline \multirow[t]{5}{*}{ Premedication } & Atropine $0.025 \mathrm{mg} / \mathrm{kg} \mathrm{im}$ & same as left \\
\hline & Acepromazine $0.05 \mathrm{mg} / \mathrm{kg}$ im once ( 15 minutes before & Ketamine $2.5 \mathrm{mg} / \mathrm{kg}$ iv \\
\hline & induction) & Midazolam $0.2 \mathrm{mcg} / \mathrm{kg}$ iv \\
\hline & Hydroxyzine $1 \mathrm{mg} / \mathrm{kg}$ im & Fentanyl $5 \mathrm{mcg} / \mathrm{kg}$ iv \\
\hline & 3 drugs im twice (30, 60 minutes before induction) & \\
\hline \multirow[t]{2}{*}{ Induction } & Thiamylal: $12.5 \mathrm{mg}$ iv & same as left or \\
\hline & & Alfaxalone $2 \mathrm{mg} / \mathrm{kg}$ iv \\
\hline \multirow[t]{5}{*}{ Maintain } & Ether: $1 \mathrm{ml} / \mathrm{kg}$ (closed, 10 minutes) $-2 \mathrm{ml} / \mathrm{kg}$ (20 30 minutes) - & Isoflurane $0.5 \%-1.5 \%$ \\
\hline & $3 \mathrm{ml} / \mathrm{kg}$ (60 minutes) - off (CA) - semi closed (declamp end) & Fentanyl $10 \mathrm{mcg} / \mathrm{kg} / \mathrm{h} \mathrm{CRI}$ \\
\hline & & Alfaxalone $0.02 \mathrm{mg} / \mathrm{kg} /$ minutes CRI \\
\hline & Pancuronium $0.04 \mathrm{mg} / \mathrm{kg}$ iv (at cooling) & same $0.06 \mathrm{mg} / \mathrm{kg}$ iv or \\
\hline & Dexamethasone $4 \mathrm{mg} / \mathrm{kg}$ iv (cooling) & $\begin{array}{l}\text { Rocuronium } 0.5 \mathrm{mg} / \mathrm{kg} \text { iv }-6 \mathrm{mcg} / \mathrm{kg} / \\
\text { minutes CRI }\end{array}$ \\
\hline \multirow[t]{4}{*}{ Others } & LMW dextran 5 ml/kg CRI (10 ml/kg/hours) & \\
\hline & Cefazolin $20 \mathrm{mg} / \mathrm{kg}$ (Before and after surgery) & \\
\hline & Heparin $400 \mathrm{IU} / \mathrm{kg}$ iv (Before CPB start) & same as left \\
\hline & Protamine $2 \mathrm{mg} / \mathrm{kg}$ iv (After CPB end) & same as left \\
\hline \multirow[t]{4}{*}{ Cardioplegia } & The first, Young solution $1 \mathrm{ml} / \mathrm{kg}+$ Oxygenated GIK $4 \mathrm{ml} / \mathrm{kg}$ & St Thomas’ II solution \\
\hline & followed the same GIK $4 \mathrm{ml} / \mathrm{kg}$ every 20 minutes & $\begin{array}{c}\text { The first, } 20 \mathrm{ml} / \mathrm{kg} \text {, followed } 10 \mathrm{ml} / \mathrm{kg} \\
\text { every } 20 \text { minutes or when action potential } \\
\text { occurred on ECG }\end{array}$ \\
\hline & & $\begin{array}{l}\text { Just before ACC release, repeat terminal } \\
\text { warm }\end{array}$ \\
\hline & & BCP (Hot shot) \\
\hline
\end{tabular}

(sHT): surface-cooling hypothermia; $(\mathrm{TH}+\mathrm{CPB})$ : moderate-deep hypothermia combined CPB.

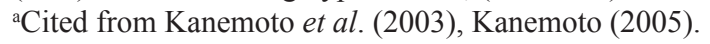

${ }^{\mathrm{b}}$ Cited from Kanemoto et al. (2010), Mihara et al. (2017).

cardioplegia was inserted into a pure-string suture in the aortic root and fixed. If hemodynamic instability was noted during this procedure, partial CPB was started. Venous blood from the jugular vein was drained to a reservoir, from a drop height of about $1 \mathrm{~m}$, and using a roller pump and a heat-exchanger, it was oxygenated with an artificial lung. Then, the oxygenated blood was sent to the LCA. After the AO was clamped behind the aortic root cannula (ARC), St Thomas II solution at $4^{\circ} \mathrm{C}$ (Jynge et al., 1981) was infused at the rate of $10 \mathrm{ml} / \mathrm{kg}$ into the coronary circulation and continued every 20 minutes at an infusion rate of $5 \mathrm{ml} / \mathrm{kg}$. After the cardiac arrest was achieved, the left atrium (LA) was opened, and the MVP was initiated at around an ET of $20^{\circ} \mathrm{C}$.

The current improved $C P B$ technique and future recommendations for $C P B$ in toy-and small-breed dogs To date, the following are the improvements in the CPB technique made by us (Mihara et al., 2017; Kanemoto et al., 2017b):
(1) Anesthesia for cardiac transplantation due to dilated cardiomyopathy (DCM) is very light to maintain stable hemodynamics in human (Kouchoukos et al., 2013c). Severe MR finally develops congestive heart failure with secondary DCM. Therefore, anesthesia was changed from deep anesthesia to light "balanced" anesthesia for premedication, anesthesia induction, and maintenance using fentanyl and isoflurane, for ensuring stable hemodynamics (Table 1, TH + CPB) (Kouchoukos et al., 2013c).

(2) On CPB, preparation of tip holes, or position adjustment of the venous cannula in the RA via transthoracic echocardiography was performed to increase drain blood volume. If drain blood volume decreased, blood volume was increased using additional transfusions, or an additional big-size drain tube was inserted from the right appendage to the RA. A smaller CPB circuit (total priming volume: $188 \mathrm{ml}$ ) (Terumo Baby RX05; Terumo Co., Tokyo, Japan) was used with a 


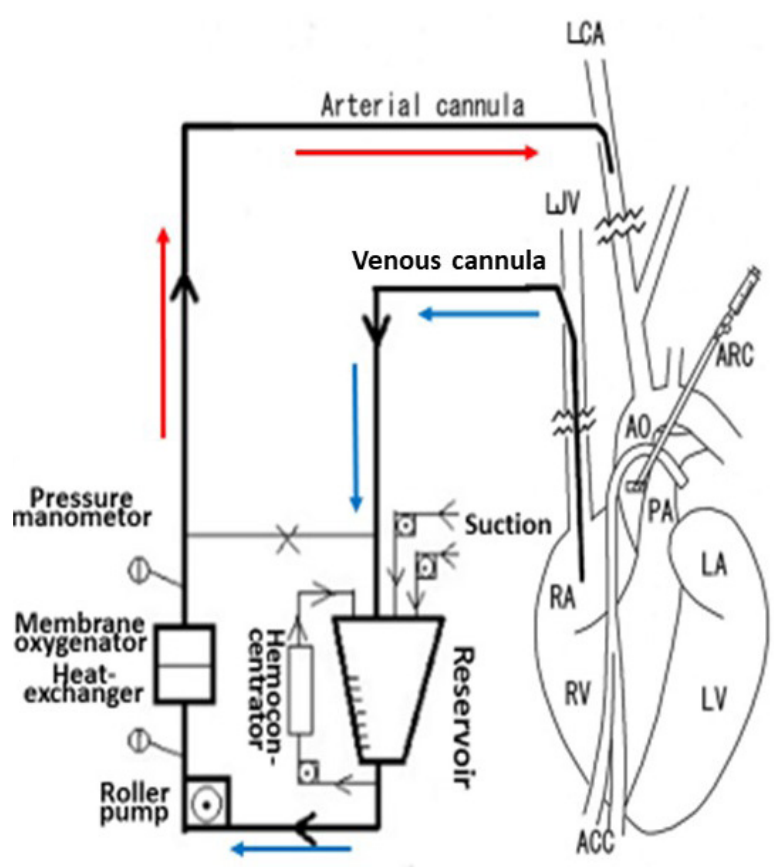

Fig. 1. Diagram of the CPB circuit with a hemoconcentrator and access to the vessels and heart for left atriotomy (partially modified CPB circuit of Kanemoto et al., 2010). Unoxygenated blood is drained by gravity through a venous cannula in the LJV; the tip of the cannula is inserted into the $\mathrm{RA}$, and the blood drains into the hard reservoir. A roller pump then returns the oxygenated blood to an arterial cannula in the LCA through a heat-exchanger and membrane oxygenator. In this CPB circuit, a hemoconcentrator is added to the ultrafiltration circuit to prevent excessive hemodilution by ultrafiltration of the same volume as that of the cardioplegic solution administered through the ARC. AO = aorta; $\mathrm{PA}=$ pulmonary artery $\mathrm{RV}=$ right ventricle; $\mathrm{LA}=$ left atrium; $\mathrm{LV}=$ left ventricle; $\mathrm{ACC}=$ aortic cross clamp.

hemoconcentrator (Aqua stream AS04; JMS Co., Tokyo, Japan) to prevent excessive hemodilution by ultrafiltration of the same volume as the cardioplegic solution (Fig. 1). The slow sHT was replaced with slow bHT and the quick rewarming was replaced with slow rewarming. The low $\mathrm{PF}$ at deep HT was also changed to a moderate $\mathrm{PF}$ at an ET of $26^{\circ} \mathrm{C}-28^{\circ} \mathrm{C}$ (moderate HT) to recover rapidly hemodynamics, although the ET decreased during prolonged ACC time. Therefore, although the time proportion of surface-cooling and blood rewarming with sHT and $\mathrm{CPB}$ was about 2:1 (Fig. 2) (Yokoyama et al., 2017), the time proportion of the rates of blood cooling and rewarming was reversed to about $1: 2$ with the bHT and CPB (Fig. 3) (Mihara et al., 2017).

(3) Additional cardioplegia with the usual cardioplegic regimen (volume: first $20 \mathrm{ml} / \mathrm{kg}$ continued at $10 \mathrm{ml} /$ $\mathrm{kg}$ every 20 minutes) using St Tomas II solution at $4^{\circ} \mathrm{C}$ was appended for strict cardioplegia if

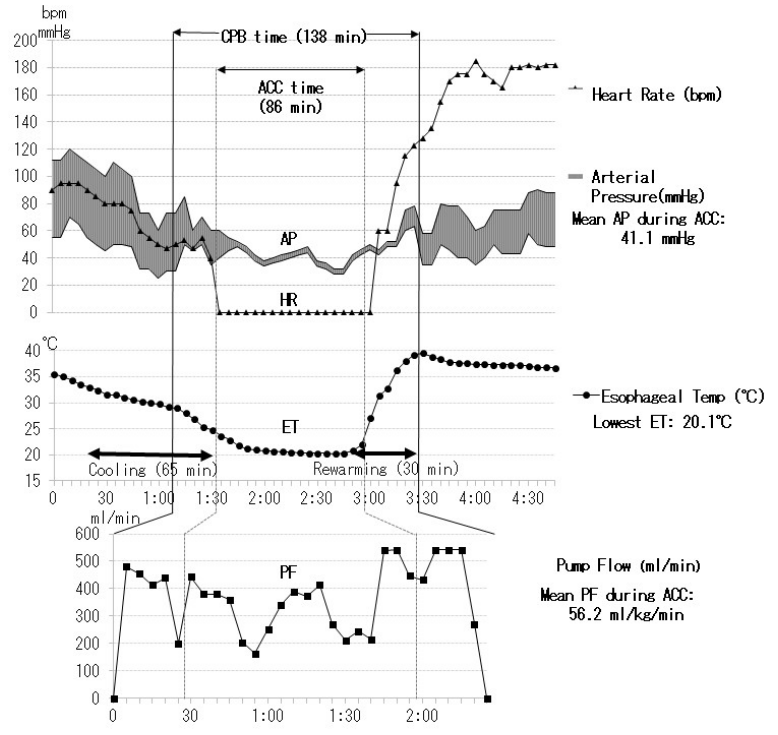

Fig. 2. Anesthesia and pump record about 1 and half hours of ACC time during complex MVP performed for severe MR in a male mixed Chihuahua aged 10 years and 2 months and with a bodyweight of $6.1 \mathrm{~kg}$ (the same dog as described in Fig. 7). ACC time: 1 hour and 26 minutes, whole pump (CPB) time: 2 hours and 18 minutes, the lowest ET: $20.1^{\circ} \mathrm{C}$, mean PF during ACC: $56.2 \mathrm{ml} / \mathrm{kg} /$ minutes, mean arterial pressure (AP) during ACC: $41.1 \mathrm{mmHg}$, extubating time from operation end: 3 hours and 20 minutes, heart rate (HR).

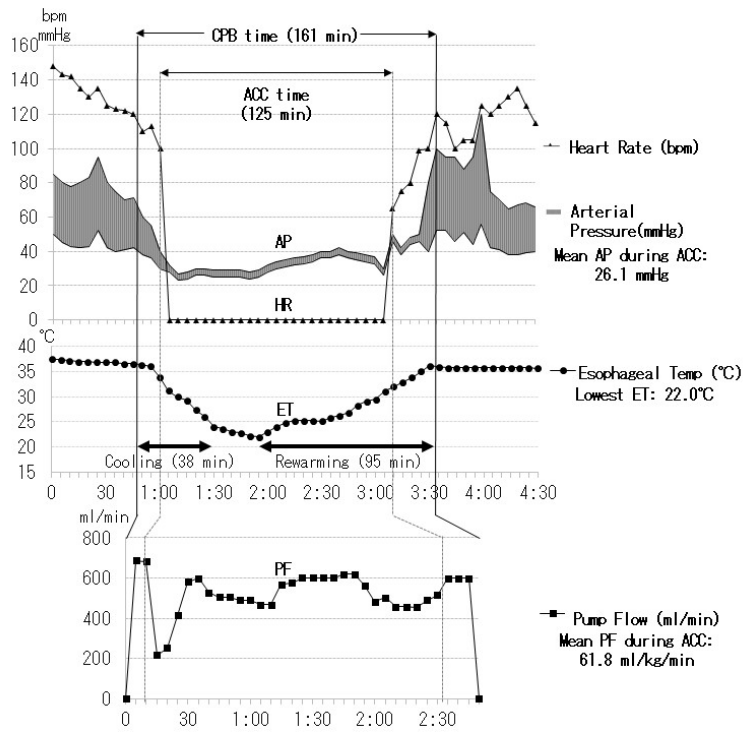

Fig. 3. Anesthesia and pump record over 2 hours of the aortic cross clamp (ACC) time during multiple MVP performed for extra-severe MR in a male Cavalier King Charles Spaniel aged 11 years and 4 months and with a bodyweight of 8.4 $\mathrm{kg}$. ACC time: 2 hours and 5 minutes, whole pump (CPB) time: 2 hours and 41 minutes, the lowest ET: $22^{\circ} \mathrm{C}$, mean PF during ACC: $61.8 \mathrm{ml} / \mathrm{kg} /$ minutes, mean arterial pressure (AP) during ACC: $26.1 \mathrm{mmHg}$, extubating time from operation end: 3 hours. 
action potential appeared (Table 1, Cardioplegia). Moreover, just before ACC release, we repeated terminal warm blood cardioplegia (BCP) (hot shot) until the appearance of self-beating (Teoh et al., 1986), which involved aspirating 10-20 ml/ $\mathrm{kg}$ warm and oxygenated blood from the sending tube using a 20-50 $\mathrm{ml}$ disposable syringe and infusion through the ARC (Table 1. Cardioplegia). In the future, although St. Thomas II is an excellent cardioplegic solution, BCP (Follette et al., 1978) and new cardioplegic solutions such as del Nido (Matte and del Nido, 2012) or Bretschneider solution (Bretschneider et al., 1975) and the new integrated BCP (Buckberg, 1995) should be assayed for admittable longer and safer ACC time, which is required for more complex MVP techniques for extra severe MR or simultaneous surgery of complicated tricuspid regurgitation (Kouchoukos et al. 2013b; Pelosi et al., 2013).

\section{Summary}

A long ACC time is required to perform a high-quality MVP surgery for severe MR. Table 1 also shows each type of cardioplegia, according to the improvement with the lapse of time. St. Thomas II solution seemed to provide excellent cardioplegia, which requires adequate volume to maintain cardiac arrest, continuing to append the final hot shot better.

As a result, we had a high success rate for several combined MVP cases for severe MR, which required a long ACC time of over 90 minutes in small dogs (Mihara et al., 2017). In addition, we reported two successful MVP cases, necessitating a long ACC time of over 2 hours, in small dogs with more severe MR (Kanemoto et al., 2017b) (Fig. 3).

MVP for MR in toy- and small-breed dogs Mitral valve plasty (MVP) for MR in humans and dogs There are two methods of mitral valve surgery, MVR using an artificial (mechanical or bioprosthetic) valve and MVP for repairing damaged self-valves (Kouchoukos et al., 2013d). In human medicine, in the past, MVR was mainstream; however, MVP has currently gained mainstream acceptance because of the good quality of life (QOL) achievable after the surgery. The advantage of MVR is good durability, although it requires life-long anticoagulant therapy. However, artificial valves are not only expensive but also not available as there are no artificial valves with a small diameter suitable for toyand small-breed dogs. There are some reports of MVR performed in large dogs (Eyster et al., 1976; Klement et al., 1987b; Orton et al., 2005). We had one case of MVR, performed in a small dog, using the smallestdiameter $(19 \mathrm{~mm})$ Bjork-Shiley aortic valve, which was sutured reverse in the mitral position; the dog died due to thrombosis after 2 years and 1 month (Taguchi et al., 2014). It seemed that it was difficult to support lifelong anticoagulant therapy in dogs. The advantage of MVP is the converse of the disadvantages of MVR, i.e., there is no need for life-span anticoagulant therapy and high-priced artificial valve. However, there is concern regarding the durability of the effect of MVP. Moreover, MVP requires trained, skilled, and experienced surgeons and some combined techniques applicable for severe MR instead of MVR in toy- and small-breed dogs. If not, residual or recurrent MR is possible. There have been a few reports of MVP performed in toy- and small-breed dogs (Kanemoto et al., 1990, 1999; Boggs et al., 1996) and some recent reports of MVP performed in small and medium-sized dogs (Kanemoto et al., 2001, 2004, 2010; Griffiths et al., 2004; Uechi, 2012; Uechi et al., 2012). However, we reported cases of long-term survival in small-breed dogs, one alive for 9 years and 1 month and another for 7 years and 10 months after MVP at 10 years of age (Kanemoto et al., 2017c). At present, we are performing MVP for all MR cases, including cases with severe MR, which was previously considered an indication for MVR.

\section{Mitral valve lesion of MR in humans and dogs}

Dr. Carpentier showed three types of mitral valve lesions in human MR: type I, a normal leaflet motion with annular dilatation; type II, a leaflet prolapse with chordal rupture or elongation; type III, a restricted leaflet motion with commissure fusion or leaflet thickening (Carpentier, 1983). In dogs, most MR lesions present with some ruptured or elongated chordae tendineae or valve prolapse (type II) due to mucoid degeneration, accompanied by secondary dilatation of the mitral valve annulus (type I) (Kittleson and Kiene, 1998).

\section{Literature review of MVP technique in humans}

Although there are many techniques of MVP in humans (Carpentier et al., 1971, 2010), it is difficult to apply these human MVP techniques without any selection to toy- and small-breed dogs because of the small heart structure and embrittlement. Therefore, MVP should be recommended for small dogs as a simple and easy technique with as little artificial material as possible. These MVP techniques are basically classified into three methods: (1) Annuloplasty (AP) for dilated mitral valve annulus, which is performed in all MVPs as this method restores the normal size of the dilated mitral valve annulus and increases the coaptation zone of both leaflets; (2) valvuloplasty (VP) for deformed valve leaflets, which is performed in severe, complex MR cases in which especially the posterior leaflet (PL) is deformed; and (3) artificial chordal reconstruction (ACR), which is performed in all MVPs, for ruptured or elongated chordae tendineae because it is the most important underlying cause for MR.

These techniques are usually combined to treat each lesion in each of the MR cases.

\section{AP techniques}

There are mainly three techniques:

1. Commissural annuloplasty (CAP) (Kay) method: an early and easy technique in which posterior and/or anterior commissure (AC) is reduced in size with a purse-suture or mattress-suture to treat regurgitation (Kay and Egerton, 1963). We used this Kay method 
in the first MVP case in a small dog (Kanemoto et al., 1990).

2. Artificial ring AP method: Carpentier and Duran rings have recently been developed and are used in human MVP; these rings are sutured to reduce the size of the mitral valve annulus (Carpentier et al., 1971; Duran and Ubago, 1976; Carpentier, 1983). However, we do not use this artificial ring because its size is too large for a small dog.

3. Semi-circular suture annuloplasty (SAP) (modified DeVega) method: in this technique, alternatively, purse-string suture with proline suture attaches the two pledgets around half the mitral valve annulus along the PL from the anterior to posterior commissure (PC) at both ends of the basal portion of the anterior leaflet $(\mathrm{AL})$ and reduces the normal size of the mitral valve annulus. We have used this method in all MVP cases (Kanemoto et al., 2001, 2004, 2010, 2017c) (Fig. 5B). Although the DeVega method was originally adapted to the tricuspid valve annulus (DeVega et al., 1973), we adapted this method to the half mitral valve annulus. The basal portion of the $\mathrm{AL}$ is not dilated because it is composed of a part of the cardiac fibrotic bony framework. The advantages of this method are that it is simple and easy, and there is no obstruction of the blood inflow from the LA to the ventricle, unlike in the case of an artificial ring. Another advantage is that it maintains the natural flexibility of the mitral valve annulus, unlike the artificial ring method. There are two reports on using polytetrafluoroethylene (PTFE) strip as a substitution for the artificial ring method in dogs, although we do not use it for the same reason stated above (Griffiths et al., 2004; Uechi, 2012; Uechi et al., 2012).

\section{VP techniques}

There are mainly two methods, triangular and rectangular resection-suture techniques:

1. Triangle plication or resection VP method is an old technique in which the redundant part of the leaflet is resected triangularly and sutured to each other (McGoon, 1960) (Fig. 4A). We used this McGoon method combined with the Kay technique in a small dog (Kanemoto et al., 1990). However, the disadvantage of this technique is the reduction of the whole size of the AL (Suri and Orsulak, 2005).

2. The rectangular or quadrangular resection VP method is a relatively recent technique and is often used to resect and suture the redundant part of the PL with artificial rings in human MVP (Carpentier et al., 1971; Carpentier, 1983; Carpentier et al., 2010) (Fig. 4B). However, we do not use this technique in small dogs because it requires careful (cut and suture) manipulation and decreases the size of the PL, and the redundant PL is rare in our experience. Instead, we used a newly devised technique, (3) direct scallopsuture (SS) VP method, which converts two or three damaged scallops with deep gaps to two scallops or

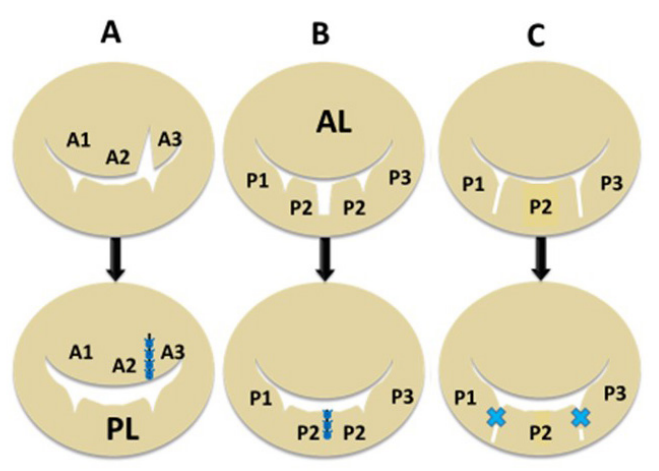

Fig. 4. Diagram showing each valvuloplasty (VP) method for each deformed valve leaflet. (A): Triangle resection VP: triangle resection and suturing of prolapsed A2-3 area for elongated chorda in the anterior leaflet (AL). (B): Rectangular resection VP: rectangular resection and suturing of the prolapsed P2 scallop in the posterior leaflet (PL). (C): Direct scallop-suture (SS) VP: direct suturing of each prolapsed scallop (P1-P2, P2-P3) with deep gaps in the PL resulting in three damaged scallops sutured to one posterior leaflet (Kanemoto et al., 2017c).
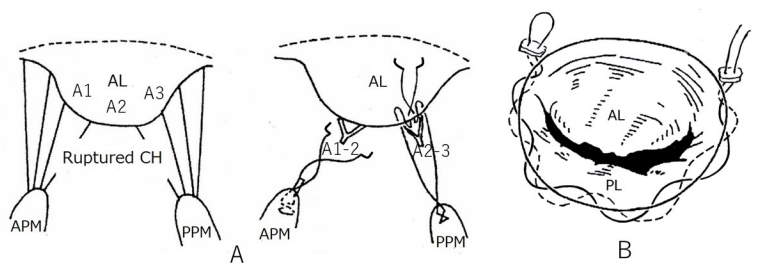

Fig. 5. Basic mitral valve plasty techniques (artificial chordal reconstruction and semi-circular suture annuloplasty) (cited from Kanemoto et al., 2017c). (A): Artificial chordal reconstruction (ACR): A preoperative diagram is shown on the left, and a perioperative diagram is shown on the right. (B): Semi-circular suture annuloplasty (SAP) (modified DeVega method). (AL): anterior leaflet (A1, A2, A3); (PL): posterior leaflet; $(\mathrm{CH})$ : chordae; (APM): anterior papillary muscle; (PPM): posterior papillary muscle.

one PL by directly suturing the prolapsed scallops with each other (Fig. 4C). This SSVP absolutely differs from a magic stitch to repair a shallow cleft in the leaflet (Carpentier et al., 2010; Varghese and Adams, 2011). The advantage is that there is no reduction in the whole size of the PL, and this method is easily adaptable to severe MR cases involving the whole PL in small dogs (Yokoyama et al., 2017).

\section{ACR techniques}

This is the most important MVP technique, which uses artificial suture for chordal reconstruction. Although ACR with pericardium and silk, nylon, Teflon, or Dacron sutures was used in ancient times, it was not used because of calcification and/or degradation with age (Rittenhouse et al., 1978). Recently, a new ACR using a PTFE suture was developed in sheep (Frater et al., 1983; Vetter et al., 1986; Revuelta et al., 1989; 
Zussa et al., 1990) and applied to human MVP (David et al., 1991, 1993). In 1995, we studied the PTFE suture as an artificial chordae in experimental dogs (Kanemoto et al., 1995, 2017a). Since then, we have used PTFE suture for ACR in all clinical MVPs performed in small dogs (Kanemoto et al., 1999, 2001, 2004, 2010) (Fig. 5A). The PTFE sutures are already covered by endocardium in 2 months, although Proline sutures are almost not covered even after 1 year (Kanemoto et al., 2017a). Moreover, PTFE sutures used for chordal reconstruction were covered with endocardium after 5 years, like the neighboring native chordae, and there was no change in the size of artificial chordae (Kanemoto et al., 1999).

Our MVP techniques for MR in toy-and small-breed $\operatorname{dogs}$

After left atriotomy, the impaired sites of the whole mitral valve were checked by ocular inspection and leak test using injected saline solution together with assessment using pre-echocardiography.

1. In MR lesions (elongated and/or ruptured chordae) limited mainly to the AL, ACR using PTFE sutures was combined with a semi-circular SAP (modified DeVega) using a Proline suture as the basic MVP technique (Kanemoto et al., 2017c). For ACR, PTFE sutures (Gore-Tex, CV-6) with two needles at both ends were sewn and fixed in the shape of a cross at the base of the ruptured chordae in the papillary muscle. Each suture was also applied in a scroll-like pattern from the ventricular side to the atrial side on both sides of the ruptured (or elongated) chordae in the AL (Fig. 5A). Both sets of sutures were ligated, after determining the length of the artificial chordae, to the opposing position of the mitral valve annulus. As a result, one ruptured (or elongated) chordae was replaced by two suture arms. For semi-circular SAP (Fig. 5B), a polypropylene (Proline 5-0, Ethicon) suture with two needles at both ends and a pledget in between was used. The sutures were alternately sewn in a semi-circular pattern in the mitral valve annulus side of the PL from the anterior to the PC site on both bases of the AL; they were attached with another pledget and ligated by inserting a sizer, with the same diameter as the $\mathrm{AL}$ area, into the valvular orifice.

2. In cases with more severe MR involving the AL, PL, and commissure leaflet (Fig. 6), in addition to basic MVP for ACR in the AL set forth above, the direct SSVP in the PL and the CAP (Kay) method in the AC were performed as additional MVP techniques. The prolapsed two scallops of the PL were sutured directly using two 6-0 Proline sutures. As the CAP method, a mattress suture with a pair of pledgets was placed at the $\mathrm{AC}$ for localized residual regurgitation (Fig. 6) (Kanemoto et al., 2017c).

3 . In cases with the most severe MR with two elongated strut chordae (A1-2 and A2-3) of the AL and four ruptured chordae (P1, P1-2, P2-3, P3) of the PL (Fig. $7 \mathrm{~A}$ ), we performed ACR using a pair of PTFE sutures, each manipulated with two needles, which were
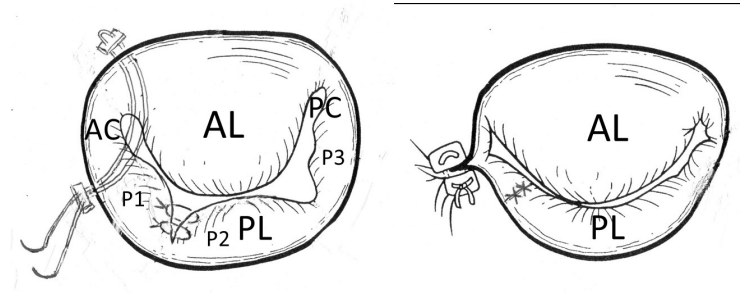

Fig. 6. Additional MVP techniques (direct SS VP method in the PL and commissural AP method in the AC in addition to the basic MVP (Fig. 5) (cited from Kanemoto et al., 2017c). The prolapsed P1 and P2 scallops in the PL were sutured directly using 6-0 Proline sutures (direct SSVP). Mattress sutures with a pair of pledgets are placed at the AC for localized residual regurgitation (Key method). $\mathrm{AL}=$ anterior leaflet; $\mathrm{PL}=$ posterior leaflet; $\mathrm{PC}=$ posterior commissure.
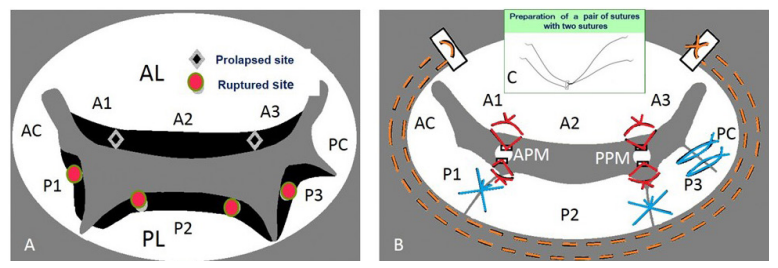

Fig. 7. Mitral valve lesion site on the mitral valve map and MVP performed in a mixed Chihuahua with the most severe MR (the same dog as described in Fig. 2) (cited from Yokoyama et al., 2017). (A) A1, A2, and A3 in the AL contact to $\mathrm{P} 1, \mathrm{P} 2$, and $\mathrm{P} 3$ in the PL, as shown in the mitral valve map. Black diamond shapes show two prolapsed chordae due to elongation in A1-2 and A2-3 in the AL. Red round shapes show four ruptured chordae in P1, P2, and P3 in the PL. Black margins of the AL and PL are remarkably hypertrophied. (B) Red lines show four ACRs performed in A1-2 and A2-3 chordae in the AL, and P1-2 and P2-3 chordae in the PL. Blue lines show three direct SS VPs performed in P1-P2, P2-P3 scallops, P3-PC scallop and leaflet with deep gaps in the PL, thus fixing all scallops in one leaflet. Brown dotted lines show SAP performed with alternately suturing from the anterior to the posterior base in the AL through the fibrous annulus of the PL. (C) (At the top middle part of Fig. 7B): Two PTFE sutures with triple-tying in the center and attached to a pledget are previously prepared. $\mathrm{AL}=$ anterior leaflet; $\mathrm{PL}$ $=$ posterior leaflet; $\mathrm{PC}=$ posterior commissure leaflet; $\mathrm{ACR}=$ artificial chordal reconstruction; $\mathrm{VP}=$ valvuloplasty.

previously prepared by triple-tying in the center and attaching to a pledget (Fig. 7B, top middle). This suture pair was sutured in the mattress form and fixed in a sandwich-shape with another pledget at the anterior papillary muscle (APM) (Fig. 7B). Next, one pair of sutures was used to suture both sides of the A1-2 chorda of the AL, followed by adjusting the length to the opposing position of the mitral valve annulus and ligation. The other pair of sutures were used to suture both the P1 and P1-2 chordae of the PL, followed by ligation (Fig. 7B, red lines). Similarly, the second pair of PTFE suture was used at the posterior papillary muscle (PPM), and one pair of sutures was used 
to suture both sides of the A2-3 chorda of the AL, followed by ligation. Another pair of sutures were used to suture both the P2 and P3 chordae of the PL, followed by ligation (Fig. 7B, red lines). For VP, the deep gaps between the P1 and P2 scallops, and the P2 and P3 scallops of the PL were sutured with a direct cross suture (SSVP) using a Proline 6-0 suture (Fig. 7B, blue lines). Finally, semi-circular SAP using a Proline 4-0 suture attached to a pledget with two needles was performed by alternately suturing from the anterior base to the posterior base of the AL, through the fibrous annulus of the PL, and attaching to another pledget, followed by ligation. This was performed for the mitral valve ring with a diameter from $20 \mathrm{~mm}$ (preoperative) to $13 \mathrm{~mm}$ (the same size as the AL area), measured using a sizer (Fig. 7B, brown lines). Based on the leak test, the gap between the P3 scallop and PC leaflet was sutured using two 6-0 Proline sutures (Fig. 7B, blue lines). As a result, MR flow mostly disappeared without mitral stenosis. Then, this dog safely underwent two major operations: a splenectomy for a splenic tumor at 9 months post-MVP and a rightlung lobectomy for lung cancer at 3 years and 5 months post-MVP (Yokoyama et al., 2017).

The current improved MVP techniques and future recommendations for MVP in toy-and small-breed dogs In 1998, the edge-to-edge technique (Alfieri method) was devised as a new simple MVP that consists of suturing the free edge of the prolapsing $\mathrm{AL}$ to the corresponding free edge of the facing PL, resulting in a double orifice valve (Maisano et al., 1998; Alfieri et al., 2001). We feared the recurrence of MR due to tearing of the sutured brittle tissue in a small dog.

In 2000, the loop technique was designed as a new conventional ACR using premeasured PTFE loops, which were preoperatively prepared as in human MVP (von Oppell and Mohr, 2000). However, it was difficult to make multiple loops because it was too short to adjust the correct length in small dogs.

Since 2016, we designed a new improved ACR, the "anchor method," which is applicable to many ACRs in small dogs because of an easy and simple technique (Mihara et al., 2018). A new suture for additional ACR was quickly prepared only to pass through a small hole, previously prepared for an anchor, without additional damage to the small papillary muscle.

In the future, we should aim to improve the highquality MVP technique, which is applicable to extrasevere MR cases in toy- and small-breed dogs instead of MVR.

\section{Summary}

The advantages of our improved MVP technique are summarized below:

1. PTFE suture used for ACR was covered by endocardium by 2 months, resembled neighboring native chordae, and did not change in size after 5 years.
2. Semi-circular SAP leads to no obstruction of blood inflow from the LA to the left ventricle (LV) and maintains the natural flexibility of the mitral valve annulus in a small dog.

3. Direct SSVP does not reduce the size of the PL by directly suturing two or three scallops and can easily repair multiple regurgitation lesions without mitral stenosis.

4. An additional CAP (Kay method) is a very simple and useful technique.

We have two cases of long-term survival in a smallbreed dog, one alive for 9 years and another for 8 years after MVP at 10 years of age.

These MVP techniques are very simple and show good durability and can result in good long-term QOL in toyand small-breed dogs.

\section{General overview}

This is the first comprehensive review about the history of open-heart surgery, CPB techniques, and MVP methods for MR in toy- and small-breed dogs.

1. We first studied sHT as an open-heart method in a small dog. Using this sHT, we succeeded in the first clinical case of MVP for MR in a small dog.

2. We then applied the deep sHT method combined with the CPB method in a small dog, sHT has been replaced with slow bHT. At present, we could improve the CPB technique to permit open heart surgery with over 2 hours of ACC time. As a result, we have been able to apply $\mathrm{CPB}$ techniques to complex congenital cardiac diseases other than MR in toy- and small-breed dogs.

3. At the same time, we developed MVP techniques suitable for treating MR in toy- and small-breed dogs. Our recommended MVP techniques include ACR, semi-circular SAP, and direct SSVP. Our MVP techniques make it possible to repair severe MR, which was previously indicated for MVR, in small dogs.

4. As of now, we have performed MVP on 102 cases in our hospital, using our open-heart techniques and improved on MVP methods during the 9 months from January 2020 to September 2020, with 98 dogs successfully discharged from the hospital (a success rate of $96.1 \%$ ) in toy- and small-breed dogs (Mihara et al., 2020 personal communications).

5. In Japan, Kanemoto et al. (2010, 2017b, 2017c), Mihara et al. (2017, 2018), Uechi (2012), Uechi et al. (2012), and other cardiac surgeons performed our improved CPB techniques and MVP methods and have achieved high success rates for MVP in toyand small-breed dogs. However, in other countries, cardiac surgeons using the usual CPB techniques and MVP methods have achieved low success rates for MVP or ceased to perform MVP in small dogs, although they succeeded in some MVP procedures in medium-sized or large dogs. It appears that our "Japan methods" of CPB and MVP are better suited for severe MR in toy- and small-breed dogs. 
6. In the future, we hope to establish highly safe openheart techniques and high-quality MVP methods in toy- and small-breed dogs.

7. Limitation of the review: This review was about open-heart techniques and MVP for MR in toy- and small-breed dogs. Therefore, some applicable CPB techniques and MVP method in medium-size or large dogs were omitted from this review.

\section{Acknowledgments}

This paper was presented, in part, at the 2014 WSAVA (the 39th World Small Animal Veterinary Association) Congress, in Cape Town, South Africa, and as a special honorary lecture at the 2017 autumn joint meeting of the 95th Jap. Soc. Vet. Aneth. \& Surg., and the 107th Jap. Soc. Vet. Cardiology in Nagoya, Japan.

We appreciate all our colleagues in the open-heart team at Chayagasaka Animal Hospital and Cardiac Surgery and Institute for Laboratory Animal Research, Nagoya University, School of Medicine.

We would like to thank Editage (www.editage.jp) for English language editing.

\section{Conflict of interest}

The authors declare that there is no conflict of interest. Authors contributions

Dr. Mihara K. (surgical assistant) and Dr. Sato K. (anesthetist) assisted in the preparation of the current manuscript on the open-heart surgery in toy- and smallbreed dogs.

\section{References}

Alfieri, O., Maisano, F., De Bonis, M., Stefano, P.L., Torracca, L., Oppizzi, M. and La Canna, G. 2001. The double-orifice technique in mitral valve repair: a simple solution for complex problems. J. Thorac. Cardiovasc. Surg. 122, 674-681.

Atkins, C., Bonagura, J., Ettinger, S., Fox, P., Gordon, S., Haggstrom, J., Hamlin, R., Keene, B., LuisFuentes, V. and Stepien, R. 2009. Guidelines for the diagnosis and treatment of canine chronic valvular heart disease. J. Vet. Intern. Med. 23, 1142-1150.

Barratt-Boyes, B.G., Simpson, M. and Neutze, J.M. 1971. Intracardiac surgery in neonates and infants using deep hypothermia with surface cooling and limited cardiopulmonary bypass. Circulation. 43(5 suppl.), I25-30.

Bigelow, W.G. and Lindsay, W.K. 1950a. Oxygen transport and utilization in dogs at low body temperatures. Am. J. Physiol. 160, 125-137.

Bigelow, W.G., Lindsay, W.K. and Greenwood, W.F. 1950b. Hypothermia; its possible role in cardiac surgery: an investigation of factors governing survival in dogs at low body temperatures. Ann. Surg. 132, 849-866.

Boggs, L.S., Dewan, S.J. and Ballard, S.E. 1996. Mitral valve reconstruction in a toy-breed dog. J. Am. Vet. Med. Assoc. 209, 1872-1876.
Bretschneider, H.J., Hübner, G., Knoll, D., Lohr, B., Nordbeck, H. and Spieckermann, P.G. 1975. Myocardial resistance and tolerance to ischemia: physiological and biochemical basis. J. Cardiovasc. Surg. (Torino). 16, 241-260.

Breznock, E.M., Vasko, J.S., Hilwig, R.W., Bell, R.L. and Hamlin, R.L. 1971. Surgical correction, using hypothermia, of an interventricular septal defect in the dog. J. Am. Vet. Med. Assoc. 158, 1391-1400.

Brown, I.W. Jr., Callaway, H.A. Jr., Harris, J.S., Hewitt, W.C. Jr., Merritt, D.H., Sealy, W.C. and Young, W.G. Jr. 1956. A method for controlled cardiac arrest as an adjunct to open heart surgery. J. Thorac. Surg. 32, 604-611.

Buckberg, G.D. 1995. Update on current techniques of myocardial protection. Ann. Thorac. Surg. 60, 805-814.

Carpentier, A. 1983. Cardiac valve surgery-the "French correction". J. Thorac. Cardiovasc. Surg. 86, 323-337.

Carpentier, A., Adams, D.H. and Filsoufi, F. 2010. Techniques in type II: posterior leaflet prolapse. In Reconstructive valve surgery. Maryland Heights, MO: Elsevier, pp: 115-126.

Carpentier, A., Delohe, A., Dauptain, J., Soyer, R., Blondeau, P., Piwnica, A., Dubost, C. and McGoon, D.C. 1971. A new reconstructive operation for correction of mitral and tricuspid insufficiency. J. Thorac. Cardiovasc. Surg. 61, 1-13.

Cohen, M. and Lillehei, C.W. 1954. A quantitative study of the azygos factor during vena caval occlusion in the dog. Surg. Gynecol. Obstet. 98, 225-232.

David, T.E., Armstrong, S., Sun, Z. and Daniel, L. 1993. Late results of mitral valve repair for mitral regurgitation due to degenerative disease. Ann. Thorac. Surg. 56, 7-14.

David, T.E., Bos, J. and Rakowski, H. 1991. Mitral valve repair by replacement of chordae tendineae with polytetrafluorethylene sutures. J. Thorac. Cardiovasc. Surg. 101, 495-501.

Davis, R.F., Kurusz, M. and Conti, V.R. 2008. Conduct of cardiopulmonary bypass. In Cardiopulmonary bypass: principles and practice, 3rd ed., Eds., Graviee, G.P., Davis, R.F., Stammers, A.H. and Ungerleider, R.M. Philadelphia, PA: Lippincott Williams \& Wilkins, pp: 543-571.

DeVega, N.G., De Rábago, G., Castillón, L., Moreno, T. and Azpitarte, J. 1973. A new tricuspid repair. Short-term clinical results in 23 cases. J. Cardiovasc. Surg. (Torino). 384-386.

Dillard, D.H., Mohri, H., Hessel, E.A. 2nd., Anderson, H.N., Nelson, R.J., Crawford, E.W., Morgan, B.C., Winterscheid, L.C. and Merendino, K.A. 1967. Correction of total anomalous pulmonary venous drainage in infancy utilizing deep hypothermia with total circulatory arrest. Circulation. 35(4 Suppl.), I105-110. 
Drew, C.E. 1961. Profound hypothermia in cardiac surgery. Brit. Med. Bull. 17, 37-42.

Duran, C.G. and Ubago, J.L. 1976. Clinical and hemodynamic performance of a totally flexible prosthetic ring for atrioventricular valve reconstruction. Ann. Thorac. Surg. 22, 458-463.

Eyster, G.E., Weber, W., Chi, S., Blair, C., Stanley, A., Friedman, H., Soloff, K., Cole, R. and Johnston, J. 1976. Mitral valve prosthesis for correction of mitral regurgitation in a dog. J. Am. Vet. Med. Assoc. 168, 1115-1118.

Follette, D.M., Mulder, D.G., Maloney, J.V. and Buckberg, G.D. 1978. Advantages of blood cardioplegia over continuous coronary perfusion or intermittent ischemia. Experimental and clinical study. J. Thorac. Cardiovasc. Surg. 76, 604-619.

Frater, R.W., Gabby, S., Shore, D., Factor, S. and Strom, J. 1983. Reproducible replacement of elongated or ruptured mitral valve chordae. Ann. Thorac. Surg. $35,14-28$.

Gibbon, J.H. Jr. 1937. Artificial maintenance of circulation during experimental occlusion of the pulmonary artery. Arch. Surg. 34, 1105-1131.

Gibbon, J.H. Jr. 1954. Application of a mechanical heart and lung apparatus to cardiac surgery. Minn. Med. 37, 171-185.

Griffiths, L.G., Orton, E.C. and Boon, J.A. 2004. Evaluation of techniques and outcomes of mitral valve repair in dogs. J. Am. Vet. Med. Assoc. 224, 1941-1945.

Hikasa, Y., Shirotani, H., Mori, C., Kamiya, T. and Asawa, Y. 1967. Open heart surgery in infants with an aid of hypothermic anesthesia. Nihon Geka Hokan. 36, 495-508.

Hikasa, Y., Shirotani, H., Satomura, K., Koike, H., Tsushimi, K., Muraoka, R., Okamoto, Y., Kawai, J., Yokota, M. and Yokota, Y. 1968. Open heart surgery in infants with using hypothermic anesthesia II. Nihon Geka Hokan. 37, 399-412.

Holmberg, D. 1933. Extracorporeal circulatory support. In Textbook of small animal surgery, 2nd ed., Ed., Slatter, D. Philadelphia, PA: W.B. Saunders, pp: 918-922.

Horiuchi, T. 1963. Radical operation for ventricular septal defect in infancy. J. Thorac. Cardiovasc. Surg. 46, 180-190.

Jynge, P., Hearse, D.J., Feuvray, D., Mahalu, W., Canković-Darracott, S., O'Brien, K. and Braimbrige, M.V. 1981. The St. Thomas' hospital cardioplegic solution: a characterization in two species. Scand. J. Thorac. Cardiovasc. Surg. Suppl. $30,1-28$.

Kanemoto, I. 2005. Hypothermia and open-heart surgery in the dog. Jpn. J. Vet. Anesth. Surg. 36, 1-9 (in Japanese with English summary).

Kanamoto, T., Kanemoto, I., Suzuki, H., Nakanishi, A., Yokoyama, S. and Chimura, S. 2003. Repair of ventricular septum defect using cardio- pulmonary bypass combined with surface-induced hypothermia and Isoflurane in a pappy dog. Nihon Juui Chikusan Shinpo. 56, 903-907 (in Japanese with English summary).

Kanemoto, I., Masumoto, T., Ohara, K., Kimura, Y. and Machida, N. 2017a. Short- and long-term results of chordal reconstruction using artificial suture material (polytetrafluoroethylene and polypropylene) in the dog. Vet. Sci. Develop. 7, 6683.

Kanemoto, I., Masumoto, T., Ohara, K., Yokoyama, H. and Noda, M. 1995. Canine mitral valvuloplasty by chordal replacement using artificial suture. In the Proceedings of the 20th World Small Animal Veterinary Association Congress, p: 654.

Kanemoto, I., Masumoto, T., Suzuki, H. and Itoh, T. 1999. A successful case of mitral valvuloplasty by chordal reconstruction with artificial suture in a dog with mitral regurgitation. Vet. Surg. 28(ACVS abst.), 395-396.

Kanemoto, I., Masumoto, T., Yokoyama, H., Noda, M, Shibata, E., Ichihara, G., Takase, K. and Ogasawara, S. 2003. The effects of ether anesthesia for surfaceinduced hypothermia on cardiopulmonary function in the dog. Jpn. J. Vet. Anesth. Surg. 34, 43-54.

Kanemoto, I., Mihara, K., Sato, K., Niimi, S., Yamada, K., Yasuhira, Y. and Watanabe, I. 2017b. Successful mitral valve plasty more than 120 minutes of aortic cross clamp time in two small dogs. In the Proceedings of the 94th Jap. J. Vet. Anesth. Surg. 48 (Suppl. 1), 332 (in Japanese).

Kanemoto, I., Mihara, K., Yokoyama, S., Kawase, K., Iguchi, K., Ando, T. and Sahashi, Y. 2009. Openheart surgery in 6 toy dogs. In the Proceedings of the 2009 Asian Meeting of Animal Medicine Specialties, p 190.

Kanemoto, I., Noguchi, H., Chimura, S., Shimizu, Y., Kobayashi, M. and Okuzawa, A. 1985. Hypothermia in dogs: I. Experimental studies with special reference to ether anesthesia. Jpn. J. Vet. Anesth. Surg. 16, 27-34 (in Japanese with English summary).

Kanemoto, I., Shibata, S., Noguchi, H., Chimura, S., Kobayashi, M. and Shimizu, Y. 1990. Successful mitral valvuloplasty for mitral regurgitation in a dog. Nihon Juigaku Zasshi. 52, 411-414.

Kanemoto, I., Shibata, S., Noguchi, H., Chimura, S., Kobayashi, M., Shimizu, Y., Doi, S. and Kurachi, H. 1989. Autotransplantation of the heart in a dog. Jpn. J. Vet. Anesth. Surg. 20, 79-83 (in Japanese with English summary).

Kanemoto, I., Shibata, S., Noguchi, H., Chimura, S., Shimizu, Y. and Kobayashi, M. 1987. Hypothermia in dogs: II. The effects of controlled ventilation on the resuscitation of the heart in experimental dogs. Jpn. J. Vet. Anesth. Surg. 18, 11-17 (in Japanese with English summary).

Kanemoto, I., Suzuki, H., Itoh, T. and Nakanishi, A. 2001. Surgical repair of mitral regurgitation 
using valvuloplasty, deep hypothermia and low flow cardiopulmonary bypass in a small dog. In the Proceedings of the 26th World Small Animal Veterinary Association Congress, p: 678.

Kanemoto, I., Suzuki, H., Taguchi, D., Yokoyama, S., Mizuno, M. and Kanamoto, T. 2004. Successful surgical repair for severe mitral regurgitation in five small-breed dogs. Vet. Surg. 33(ACVS abst.), 435.

Kanemoto, I., Taguchi, D., Mihara, K., Kawase, K., Sato, K., Iwata, K. and Iwanaga, K. 2017c. Longterm survival of two dogs after mitral valve plasty. Vet. Sci. Develop. 7, 6335.

Kanemoto, I., Taguchi, D., Yokoyama, S., Mizuno, M., Suzuki, H. and Kanamoto, T. 2010. Open heart surgery with deep hypothermia and cardiopulmonary bypass in small and toy dogs. Vet. Surg. 39, 674-679.

Kay, J.H. and Egerton, W.S. 1963. The repair of mitral insufficiency associated with ruptured chordae tendineae. Ann. Surg. 157, 351-360.

Khonsari, S. and Sintek, C.F. 2003. Surgical approach to the heart and great vessels. In Cardiac surgery: safeguards and pitfalls in operative technique, 3rd ed, Eds., Khonsari, S. and Sintek, C.F. Los Angeles, CA: Lippincott Williams \& Wilkins, pp: 2-17.

Kittleson, M.D. and Kiene, R.D. 1998. Myxomatous atrioventricular valvular degeneration. In Small animal cardiovascular medicine. Eds., Kittleson, M.D. and Kiene, R.D. Kimberton, PA: Mosby, pp: 297-318.

Klement, P., del Nido, P.J., Mickleborough, L., MacKay, C., Klement, G. and Wilson, G.J. 1987a. Technique and postoperative management for successful cardiopulmonary bypass and open-heart surgery in dogs. J. Am. Vet. Med. Assoc. 190, 869-874.

Klement, P., Feindel, C.M., Scully, H.E., Mesher, E., Klement, G., del Nido, P. and Wilson, G.J. 1987b. Mitral valve replacement in dogs: surgical technique and postoperative management. Vet. Surg. 16, 231-237.

Komtebedde, J., Ilkiw, J.E., Follette, D.M., Breznock, E.M. and Tobias, A.H. 1993. Resection of subvalvular aortic stenosis. Surgical and perioperative management in seven dogs. Vet. Surg. 22, 419-430.

Kouchoukos, N.T., Blackstone, E.H., Hanley, F.L. and Kirklin, J.K. 2013a. Hypothermia, circulatory arrest, and cardiopulmonary bypass. In Kirklin/barrattboyes cardiac surgery, 4th ed., Eds., Kouchoukos, N.T., Blackstone, E.H., Hanley, F.L. and Kirklin, J.K. Philadelphia, PA: Elsevier, pp: 68-132.

Kouchoukos, N.T., Blackstone, E.H., Hanley, F.L. and Kirklin, J.K. 2013b. Myocardial management during cardiac surgery with cardiopulmonary bypass. In Kirklin/barratt-boyes cardiac surgery, 4th ed. Eds., Kouchoukos, N.T., Blackstone, E.H., Hanley, F.L. and Kirklin, J.K. Philadelphia, PA: Elsevier, pp: 133-162.
Kouchoukos, N.T., Blackstone, E.H., Hanley, F.L. and Kirklin, J.K. 2013c. Anesthesia for cardiovascular surgery. In Kirklin/barratt-boyes cardiac surgery, 4th ed. Eds., Kouchoukos, N.T., Blackstone, E.H., Hanley, F.L. and Kirklin, J.K. Philadelphia, PA: Elsevier, pp: 164-175.

Kouchoukos, N.T., Blackstone, E.H., Hanley, F.L. and Kirklin, J.K. 2013d. Mitral valve disease. In Kirklin/barratt-boyes cardiac surgery, 4th ed. Eds., Kouchoukos, N.T., Blackstone, E.H., Hanley, F.L. and Kirklin, J.K. Philadelphia, PA: Elsevier, pp: 484-536.

Lew, L.J., Fowler, J.D., Egger, C.M., Thomson, D.J., Rosin, M.W. and Pharr, J.W. 1997. Deep hypothermic low flow cardiopulmonary bypass in small dogs. Vet. Surg. 26, 281-289.

Lewis, F.J. and Taufic, M. 1953. Closure of atrial septal defects with the aid of hypothermia; experimental accomplishments and the report of one successful case. Surgery. 33, 52-59.

Lillehei, C.W., Cohen, M., Warden, H.E., Ziegler, N.R. and Varco, R.L. 1955. The results of direct vision closure of ventricular septal defects in eight patients by means of controlled cross circulation. Surg. Gynecol. Obstet. 101, 446-466.

Lolley, D.M., Hewitt, R.L. and Drapanas, T. 1974. Retroperfusion of the heart with a solution of glucose, insulin, and potassium during anoxic arrest. J. Thorac. Cardiovasc. Surg. 67, 364-370.

Maisano, F., Torracca, L., Oppizzi, M., Stefano, P.L., D’Addario, G., La Canna, G., Zogno, M. and Alfieri, O. 1998. The edge-to-edge technique: a simplified method to correct mitral insufficiency. Eur. J. Cardiothorac. Surg. 13, 240-246.

Matte, G.S. and del Nido, P.J. 2012. History and use of del Nido cardioplegia solution at Boston Children's Hospital. J. Extra. Corpor. Technol. 44, 98-103.

McGoon, D.C. 1960. Repair of mitral insufficiency due to ruptured chordae tendineae. J. Thorac. Cardiovasc. Surg. 39, 357-362.

Mihara, K., Kanemoto, I., Sato, K., Mori, T., Abe, H., Niimi, S., Yamada, K., Ohira, K., Andou, T. and Hirakawa, A. 2017. Open heart surgery with deep hypothermic cardiopulmonary bypass and more than 90 minutes of aortic cross clamp time in 10 small dogs. Vet. Sci. Develop. 7, 6442.

Mihara, K., Sato, K., Niimi, S., Yasuhira, Y., Watanabe, I., Suzuki, Y., Nagura, S. and Kanemoto, I. 2018. The results using anchor method as a quick MVP technique to repair all-around lesions for severe MR in six Cavalier King Charles Spaniel dogs. In the Proceeding of the 108th Japanese Society of Veterinary Cardiology, pp: 304.

Mohri, H., Dillard, D.H., Crawford, E.W., Martin, W.E. and Merendino, K.A. 1969. Method of surface-induced deep hypothermia for open-heart surgery in infants. J. Thorac. Cardiovasc. Surg. 58, 262-270. 
Orton, E.C. 2003. Cardiac surgery. In Textbook of small animal surgery, 3rd ed., Ed., Slatter, D. Philadelphia, PA: W.B. Saunders, pp: 955-986.

Orton, E.C., Hackett, T.B., Mama, K. and Boon, J.A. 2005. Technique and outcome of mitral valve replacement in dogs. J. Am. Vet. Med. Assoc. 226, 1508-1511.

Pelosi, A., Anderson, L.K., Paugh, J., Robinson, S. and Eyster, G.E. 2013. Challenges of cardiopulmonary bypass- a review of the veterinary literature. Vet. Surg. 42, 119-136.

Revuelta, J.M., Garcia-Rinaldi, R., Gaite, L., Val, F. and Garijo, F. 1989. Generation of chordae tendinae with polytetrafluorethylene stents. Results of mitral valve chordal replacement in sheep. J. Thorac. Cardiovasc. Surg. 97, 98-103.

Rittenhouse, E.A., Davis, C.C., Wood, S.J. and Sauvage, L.R. 1978. Replacement of ruptured chordae tendineae of the mitral valve with autologous pericardial chordae. J. Thorac. Cardiovasc. Surg. 75, 870-876.

Spohn, K., Kolb, E., Heinzel, J. and Kratzert, R. 1959. Deep hypothermia under 20 degree C; WatanabeOkamura-Ishikawa method; physical efficiency in open heart surgery in animal experiment. Langenbecks Arch. klin. Chir. Ver. Dtsh. Z. Chir. 290, 365-428 (in German).

Suri, R.M. and Orsulak, T.A. 2005. Triangular resection for repair of mitral regurgitation due to degenerative disease. Oper. Tech. Thorac. Cardiovasc. Surg. 10, 194-199.

Taguchi, D., Kanemoto, I., Yokoyama, S., Mizuno, M. and Washizu, M. 2014. Mitral valve replacement with a mechanical valve for severe mitral regurgitation in a small dog. Case Report Vet. Med. 892625, 1-5.

Teoh, K.H., Christakis, G.T., Weisel, R.D., Fremes, S.E., Mickle, D.A., Romaschin, A.D., Harding, R.S., Ivanow, J., Madonik, M.M., Ross, I.M., McLaughlin, P.R. and Baird, R.J. 1986. Accelerated myocardial metabolic recovery with terminal warm blood cardioplegia. J. Thorac. Cardiovasc. Surg. 91, 888-895.

Uechi, M. 2012. Mitral valve repair in dogs. J. Vet. Cardiol. 14, 185-192.
Uechi, M., Mizukoshi, T., Mizuno, T., Mizuno, M., Harada, K., Ebisawa, T., Takeuchi, J., Sawada, T., Uchida, S., Shinoda, A., Kasuya, A., Endo, M., Nishida, M., Kono, S., Fujiwara, M. and Nakamura, T. 2012. Mitral valve repair under cardiopulmonary bypass in small-breed dogs: 48 cases (2006-2009). J. Am. Vet. Med. Assoc. 240, 1194-1201.

Varghese, R. and Adams, D.H. 2011. Techniques for repairing posterior leaflet prolapse of the mitral valve. Oper. Tech. Thorac. Cardiovasc. Surg. 16, 293-308.

Vetter, H.O., Burack, J.H., Facter, S.M., Macaluso, F. and Fater, R.W.M. 1986. Replacement of chordae tendinae of the mitral valve using the new expanded PTFE suture in sheep. In Biologic and bioprosthetic valves, Eds., Bordnar, E. and Yacoub, M. New York, NY: New York Medical Books, pp: 772-784.

von Oppell, U.O. and Mohr, F.W. 2000. Chordal replacement for both minimally invasive and conventional mitral valve surgery using premeasured Gore-Tex loops. Ann. Thorac. Surg. 70, 2166-2168.

Watanabe, A., Okamura, H., Takahashi, T. and Noro J. 1956. An experimental study on cardiac resuscitation after long cessation of inflow to the heart under severe low temperature. Sougou. Igaku. 13, 771-780 (in Japanese).

Weirich, W.E., Smith, C.R., Incopera, F.P. and Mandelbaum, I. 1973. Hypothermia for cardiac arrest surgery in the dog. J. Am. Anim. Hosp. Assoc. 9, 540-547.

Yokoyama, S., Kanemoto, I., Mihara, K., Ando, T., Kawase, K., Sahashi, Y. and Iguchi, K. 2017. Treatment of severe mitral regurgitation caused by lesions in both leaflets using multiple mitral valve plasty techniques in a small dog. Open Vet. J. 7, 328-331.

Zussa, C., Frater, R.W., Polesel, E., Galloni, M. and Valfré, C. 1990. Artificial mitral valve chordae: experimental and clinical experience. Ann. Thorac. Surg. 50, 367-373. 